\title{
Águas termais como temática no ensino de ciências
}

\author{
Thermal water as a theme in science education
}

Helen Nayara Oliveira Santos ${ }^{1}$, Thamires Ferreira Barbosa De Oliveira ${ }^{1}$, Edward Bertholine de Castro $^{2}$, Eduardo Ribeiro Mueller ${ }^{3}$ e Geison Jader Mello ${ }^{4}$

${ }^{1}$ Licenciada em Ciências da Natureza, Núcleo de Jaciara, Campus São Vicente, Instituto Federal de Mato Grosso, Jaciara,

MT, Brasil.

2Mestre em Ensino de Ciências, Universidade Federal de Mato Grosso, Cuiabá, MT, Brasil

${ }^{3}$ Doutorando em Ciências e Matemática, Universidade Federal de Mato Grosso, Pontal do Araguaia/MT, Brasil.

${ }^{4}$ Doutor em Física Ambiental, Núcleo de Jaciara, Campus São Vicente, Instituto Federal de Mato Grosso, Jaciara, MT, Brasil.

\section{Resumo}

O ensino de Ciência Natural ainda hoje é baseado na mera transmissão de conteúdos, ao uso de livro didático, giz e quadro negro. Esta postura por parte dos professores desestimula os estudantes a aprender, sendo assim é de primordial importância a utilização de propostas metodológicas que incentivem os estudantes, tanto para que aprendam de forma significativa e contextualizada, quanto se tornarem cidadãos críticos, e identifique as inter-relações dos conceitos específicos das ciências para o entendimento dos fenômenos naturais. O trabalho tem como tema as águas termais mostrando a importância do tema em todos os detalhes, destacando de forma clara a água e suas aplicações em várias formas. O objetivo do estudo foi descrever como o tema da água e seu tratamento é abordado dentro do ensino de ciências, no qual o ensino-aprendizado ocorre de maneira processual e contextualizada.

Palavras-chave: águas termais, ensino de ciências.

\begin{abstract}
The teaching of natural science today is based on the mere transmission of content, the use of textbooks, chalk and blackboard. This posture by teachers discourage students learn, so it is of paramount importance the use of methodological proposals that encourage students both to learn in a meaningful and contextualized way, as they become critical citizens, and identify the interrelationships the specific concepts of science to the understanding of natural phenomena. The work has as its theme the thermal waters showing the importance of the subject in every detail, highlighting clearly the water and its applications in various forms. The aim of the study was to describe how the theme of water and its treatment is covered within the science education in which teaching and learning takes place procedural and contextualized way.
\end{abstract}

Keywords: thermal water, science teaching. 


\section{Introdução}

A disciplina de Ciências Naturais, enquanto componente curricular do Ensino Fundamental, é necessária para a ampliação dos saberes no contexto da educação escolar. Nessa ótica, o seu papel se fundamenta como subsídio de apreensão do planeta e suas transformações, estabelecendo o homem como indivíduo participativo e parte integrante do Universo.

Mas afinal por que não melhorar a forma de ensinar, criar meios para que o aluno interaja com o que se está estudando? É possível alcançar esse fim trabalhando estratégias metodológicas que facilitem o processo de ensino-aprendizagem. Desde então surgiu à ideia de estar trabalhando esta temática, sendo que este conteúdo é de suma importância, pois o fornecimento de água da cidade vem de poços artesianos, visto que as maiorias dos alunos não sabem ou não compreendem como são formadas as águas termais optamos em trabalhar essa temática para levar informação e conhecimento sobre o assunto. Os Parâmetros Curriculares Nacionais (PCNs) são definidos como referenciais comuns para a educação no ensino fundamental em todo o Brasil, pois não se auto-denominam um currículo acabado e obrigatório, mas o seu nível de detalhamento faz um currículo do ensino fundamental que possa orientar as ações educativas no ensino obrigatório e melhorar sua qualidade nas escolas brasileiras.

A orientação proposta reconhece a importância da participação construtiva do aluno e a intervenção do professor para a aprendizagem que favoreça o desenvolvimento das capacidades necessárias à formação do indivíduo, pois o processo de ensino e aprendizagens não se desenvolve por etapas, mas que o objeto do conhecimento é complexo e porque o processo cognitivo não acontece por justaposição e sim por reorganização do conhecimento a partir do que já existe como experiência. Muitas abordagens educativas são esclarecidas pelos PCNs, como a importância da autonomia do aluno, interação, cooperação e decisões sobre avaliação e uso de tecnologias de comunicação e expressão como processo de construção de novos conhecimentos.

O objetivo deste trabalho é compreender a formação das águas termais de Juscimeira, pois a cidade é privilegiada por vários balneários e todos com águas termais, mas essa água não é apenas um privilégio dos balneários na cidade, há três poços artesianos que fornece essa água a todas as residências. Os poços jorram 24 horas uma quantidade de $30 \mathrm{mil}$ litros/h, essa água é utilizada para todos os fins, com isso o gasto nas residências é excessivo sem controle ou precaução alguma. E por falta de conhecimento desses estudantes sobre a formação dessas águas vimos à necessidade de realizar este trabalho, para que os alunos possam perceber a importância e necessidade de economizala e preservar tal recurso natural precioso, e com isso diminuindo a escassez.

\section{Revisão Bibliográfica}

Neste capitulo são apresentadas as revisões de literatura desse trabalho, que por sua vez é dividida em duas frentes. A primeira frente é composta pelo tema "ensino de ciências", seus problemas e suas expectativas, e a segunda parte é composta pelo tema gerador "águas termais".

\subsection{Ensino de Ciências como temática}

O ensino de ciências é de suma importância nas escolas, através dele os alunos tem a possibilidade de descobrir e de conhecer o que acontece em sua volta podendo se tornar uma pessoa diferente através dos conhecimentos obtidos com os fatos que ocorrem em seu cotidiano (FREIRE, 2005)

Segundo Freire (2005) podemos dizer que ciências pode ser vista como instrumento de transformação no qual possibilita ao aluno aprender a investigar, analisar, compreender buscar os conceitos relacionados à natureza obtendo interesse com tudo que acontece ao seu redor. Para que os conteúdos de ciências possam ser bem esclarecidos o professor deve trabalhar em cima de sua metodologia de ensino para que sua aula seja bem elaborada colaborando para um melhor 
entendimento do aluno, sempre observando para que não ocorra o uso de vocabulário impróprio utilizando metodologias adequadas para os alunos aprenderem melhor.

[...] Eis ai a concepção "bancária" da educação, em que a única margem de ação que se referem aos educandos é a de receberem os depósitos, guardá-los e arquivá-los. Margem para serem colecionadores ou fixadores das coisas que arquivam. [...] Arquivados, porque fora da busca, fora da práxis, os homens não podem ser. Educador e educandos se arquivam na medida em que, nesta distorcida visão da educação, não há criatividade, não há transformação, não há saber (FREIRE 2005, p .66).

As maiorias das escolas necessitam de materiais didáticos, pois grandes partes da escola são carentes em relação a esses recursos didáticos, com isso o educador não deve apenas se prender apenas aos recursos da escola deve buscar entre outros meios para construir e desenvolver o conhecimento (PILLETE, 2006). E ainda:

[...] As dificuldades com relação aos recursos didáticos são grandes, pois a maioria das escolas é carente. Assim cabe ao professor esforçar-se por conhecer, adaptar-se e saber aproveitar as oportunidades, procurando usar recursos audiovisuais com quadro-de-giz, esquemas, desenhos, flanelógrafos, gravuras, murais, slides, filmes, retroprojetor experiências, videocassete, etc (PILLETE, 2006, p.281).

Diante disso o professor deve utilizar ao seu favor o uso de materiais e métodos que estejam ao seu alcance aproveitando ao máximo todas as oportunidades para estar despertando o interesse dos seus alunos e com isso facilitando o seu aprendizado (PILLETE, 2006).

Com o decorrer dos dias as pessoas aprendem o tempo todo ou por que precisam ou por interesse, com o passar dos dias nossa convivência com outras pessoas, ou por fatores naturais aprendemos varias coisas sejam elas por necessidade, interesse, vontade, seja qual for o motivo estamos adquirindo conhecimento a todo o momento em nossa vida (PILLETE, 2006).

A aprendizagem não é formada por meros tópicos ou um simples assunto, é adquirir o conhecimento em todos os sentidos tanto no sentido tradicional, nas habilidades tanto manuais quanto intelectuais, até mesmo durante nossos relacionamentos com outras pessoas ou com nossos próprios sentimentos, valor pode ocorrer trocas de conhecimento que ira nos favorecer ao longo de toda nossa vida. (DELIZOICOV et al., 2009, pg.123).

Não desconhecemos as dificuldades enfrentadas pelos educadores, no cotidiano da escola deparam-se muitas vezes com a desesperança provocada pela exclusão social e pela violência urbana, enfrentam a competição da mídia no apelo constante ao consumo, ao "ter mais" e ao individualismo, contrário à solidariedade edificante. Todavia na pedagogia freireana, e na capacidade humana se faz necessidade de impulsionar um projeto educativo, levando o educador comprometido a vislumbrar no enfrentamento dos conflitos e das adversidades da escola pública, o sentido mais autêntico da tarefa educativa, ou seja, a construção do humano forjado no desejo de "ser mais" e, em consequência, pela capacidade de sonhar. Na sua exortação ao compromisso político dos educadores (FREIRE, 2009).

[...] Na verdade toda vez que o futuro seja considerado como um predado, ora porque seja a pura repetição mecânica do presente (...), ora porque seja o que teria de ser, não há lugar para a utopia, portanto para o sonho, para a opção, para a decisão, para a espera na luta... Não há lugar para a educação. Só para o adestramento. (FREIRE, 2009, p. 92)

O conhecimento seja ele científico ou popular não pode ser descontextualizado, pois os temas abordados têm relação com questões que buscam respostas para atos ressaltantes em nosso mundo, e com o uso de novas tecnologias faz com que pensamos qual o efeito de seu uso excessivo ao decorrer do tempo em relação a nossa sociedade, por isso tem que haver uma preocupação com as gerações seguintes para que eles possam ter um compromisso com o nosso plante, ainda Santos (2009):

[...] sala de aula tem de transformar se ela própria em campo de possibilidades de conhecimento dentro do qual há que optar. Optam os alunos tanto quanto os professores e as opções de uns e de outros não têm de coincidir nem são irreversíveis. As opções não assentam exclusivamente em idéias já que as idéias deixaram de ser desestabilizadoras no nosso tempo. Assentam igualmente em emoções, sentimentos e paixões que conferem aos conteúdos curriculares sentidos inesgotáveis. (SANTOS, 2009, p.19) 
A busca de novos saberes faz com que percebemos que somos incompletos, por isso a importância de se procurar novos conhecimentos se faz importante, para possamos está sempre se inovando em relação à aprendizagem, mas sem deixar de ser rigoroso com os conteúdos abordados, e com isso levar o sujeito a ter curiosidade do que se está sendo observado. Segundo Freire (2009, p. 27) [...] quanto mais criticamente se exerça a capacidade de aprender tanto mais se constrói e desenvolve o que venho chamando 'curiosidade epistemológica', sem a qual não alcançamos o conhecimento cabal do objeto.

Portanto, fica evidente que a escola de Educação não tem função de substituir a família nas suas obrigações, ela é um complemento onde deverá estar integrado com a família em prol do pleno desenvolvimento dos alunos. Ao adentrar na escola, os alunos iniciam o contato com pessoas, ambientes, objetos diferentes, muitas vezes desconhecido, e é a partir desta diversidade que o aluno se enriquece e aprende a conviver socialmente. No período de adaptação, o aluno necessita de tempo para se ajustar ao ritmo coletivo e, mesmo após esse período, é preciso prever alternativas que atendam as peculiaridades da instituição, mas respeitem a integridade física e emocional dos alunos.

Segundo Almeida \& Casarin (2002), escola tem o dever de criar condições para oferecer educação e cuidados de forma indissociável em conjunto com as famílias e a comunidade. Primeiramente, é preciso garantir que a organização do tempo, do espaço e da rotina, tenha como inquietação maior, a garantia de uma vivência plena da infância e tenha como foco a criança contemplando ao máximo as suas necessidades. Ao atendendo a essas necessidades, a escola deve estipular tempos específicos para atividades lúdicas, sendo estas, indispensáveis ao desenvolvimento do aluno.

[...] Para manter o aluno na escola de forma que ele se sinta motivado e acolhido é imprescindível que o professor utilize-se de vários métodos em sua prática, sendo estes de forma lúdica e descontraída. Com a intenção de aproximar o aluno da escola e mantê-lo motivado neste ambiente, deve-se utilizar recursos que diversifiquem a prática pedagógica, buscando tornar o espaço da sala de aula aconchegante, divertido, descontraído, propiciando o aprender dentro de uma visão lúdica, criando um vínculo de aproximação/união entre o professor e o aluno (ALMEIDA \& CASARIN, 2002).

Desta forma a escola deve ser considerada como uma segunda casa para os alunos, local onde devem ser acolhidos e motivados a todo o momento.

Um dos objetivos dos Parâmetros Curriculares Nacionais (PCNs), no que se refere ao ensino de ciências naturais é o saber como utilizar diferentes fontes de informações e recursos tecnológicos nas metodologias diferenciadas e fontes de informação tudo que possa contribuir na aprendizagem e na motivação do aluno, para um olhar construtivo e reflexivo (BRASIL, 1997).

Por muito tempo o ensino de ciências era feito com aulas onde o professor apenas transmitia o conhecimento através de aulas expositivas, onde o mesmo somente explicava a matéria e aluno prestava atenção com o dever de obter o conhecimento expressado pelo professor. Os alunos não podiam se quer participar das aulas através de questionamento sobre o assunto, com isso não havia interação com o professor e até mesmo com o conteúdo (BRASIL,1997).

De acordo com (MARTINS, 1997) o ensino adquirido de forma mais interativa, explicativa de maneira diferenciada mais esclarecedora proporciona que os alunos que formulem hipótese, saibam fazer argumentações, identifique os fatos com melhor clareza, com isso os alunos tem a concepção de ser um integrante ativo da construção do momento de adquiri e construir conhecimento.

Através da utilização da metodologia de aulas de campo como recurso didático no processo do Ensino de Ciências é possível melhorar a aprendizagem dos estudantes. Através dessas práticas pedagógicas também possibilita aos alunos um contexto de cidadania e análise crítica sobre seu espaço de vivência e de construção.

As Aulas Campos, também são conhecidas como saída de campo, trabalho de campo, excursão, aula prática, atividade extraclasse entre outras designações, proporciona atividades de forma pronunciada e associada entre os componentes curriculares da área de Ciências da Natureza. Percebese, apesar dessa possibilidade reconhecida pelos professores, poucas experiências têm sido operacionalizadas nas unidades escolares (CASTRO, 2012). 
De acordo com Castro (2012) as aulas de campo não são um recurso pedagógico que os professores utilizam, por conta de serem atividades praticadas fora da escola.

No PCNs(1998) [...] Para que o trabalho de campo ou excursão tenha significado para a aprendizagem, e não apenas como atividade de lazer, é importante que o professor tenha clareza dos diferentes conteúdos e objetivos que pretende explorar. Esta definição é fundamental para que a atividade seja bem compreendida pelos estudantes.

\section{2 Águas termais como temática}

Uma forma de proporcionar aos alunos um conhecimento mais esclarecedor do conteúdo que esta sendo estudado é a utilização das aulas de campo fazendo o uso de ambientes naturais para facilitar a aprendizagem, como no caso das balneárias termas presente no município de Juscimeira e dos poços artesianos que fazem o abastecimento da cidade, pois através deles os alunos podem visualizar os resultados das atividades propostas.

A água é o bem mais precioso dos Seres Vivos, é utilizadas em várias atividades nas residências, indústrias, agropecuárias, entre outros e com isso gera o desperdício exagerado, e se não for tratada de forma adequada pode haver a contaminação de fontes de água subterrâneas (SOUZA et al., 2014).

Souza et al. (2014) afirma que [...] na Terra tudo é mantido graças a presença desse liquido vital, as cidades, as industrias, as plantações e até mesmo o oxigênio que se respira. A maior parte do planeta é coberta por água sendo que $3 \%$ é água doce, e o restante é de água salgada. Com a população aumentando a cada dia, o desperdício fica mais eminente, por isso a importância da preservação desse recurso, se não houver uma sensibilização da população em relação ao desperdício e a preservação pode haver a escassez dessas águas.

[...] Antigamente não existiam chuveiros e nem válvulas de descarga, que são os grandes vilões no desperdício da água tratada, trazendo um grande prejuízo para o Meio Ambiente. Além de utilizar recursos naturais, as indústrias acabam contaminando todo o planeta com seus produtos químicos despejados na natureza sem tratamento (SOUZA et al., 2014).

As principais fontes de suprimento de água para os seres humanos podem ser superficiais ou subterrâneas. As águas provenientes de fontes superficiais são encontradas em rios, riachos e lagos. As águas subterrâneas são encontradas no subsolo, formando os lençóis subterrâneos (CUTRIM \& REBOUÇAS, 2005).

A região de Juscimeira-MT é formada pela Bacia do Paraná confinada no Aquífero Furnas. Os aquíferos Furnas são consideradas um dos mais importantes devidos sua localização e qualidade de suas águas, nas regiões onde se localiza as aquíferas Furnas são comuns o acontecimento de águas termais e poços jorrantes (SILVA et al., 2008).

Na cidade de Juscimeira é comum à ocorrência de águas termais é uma das principais economias da região, o abastecimento da cidade é devido a poços artesianos que jorram 24 horas por dia, na cidade há quatros Balneários termais fora os distritos da cidade.

Segundo Silva et al. (2018) o poço do Balneário Chuveirão, é relatado pelos proprietários como possuindo $150 \mathrm{~m}$ de profundidade. Está revestido em tubo de aço de 8" de diâmetro e produz cerca de $20 \mathrm{~m}^{3} / \mathrm{h}$ em regime artesiano jorrante. Este poço é famoso na região e para aqueles que alguma vez passaram pelo caminho entre Jaciara e Rondonópolis, até algum tempo atrás era facilmente observável da estrada pela coluna de água jorrando no alto da colina logo após Juscimeira, caminhado rumo sul.

Os poços do DAE Juscimeira representam duas gerações de poços. Foi construído pela antiga SANEMAT na década de 80 e apesar da proximidade do Balneário Chuveirão, não apresenta artesianismo jorrante. Sua profundidade, segundo os responsáveis do DAE Juscimeira é de $181 \mathrm{~m}$ (SILVA et al., 2008). Já o segundo poço do DAE Juscimeira, na época da amostragem, havia recentemente sido perfurado e instalado. Não havia precisão nos dados de profundidade do mesmo, sendo relatados $170 \mathrm{~m}$ e apenas a residência que cedeu espaço para instalação do poço estava interligada. 
O Thermas Marihá, instalou em 2005 um poço para abastecimento de um complexo turístico. Com $289 \mathrm{~m}$ de profundidade, está revestido até $176 \mathrm{~m}$ e mantém uma produção ao redor de $50 \mathrm{~m} / \mathrm{h}$ (SILVA et al., 2008).

Não só apenas em Juscimeira, mas em varias outras cidades inclusive em nossa região há a utilização das águas termais para o meio turístico, esse fenômeno leva o interesse de varias pessoas que vão à busca dessas águas por acreditarem que é beneficiaria a saúde por ter uma temperatura superior a $40^{\circ} \mathrm{C}$.

[...] Presentes em todos os continentes, fontes termais ocorrem em quase toda situação tectônica concebida. Algumas parecem emanar de fontes cristais profundas algumas de fontes magmáticas, e outras parecem ser originadas da recarga da água subterrânea que localmente pode ter se movido para grandes profundidades, emanando-se rapidamente, sem tempo para que ocorra o reequilíbrio térmico (SILVA et al., 2008).

De acordo com Souza \& Orlando (2010) águas termais são águas de chuvas que penetram no solo chegando à superfície com temperatura muito elevada com profundidade de cerca de 1500 metros, por conta de uma fissura no subsolo e por essa água subir com uma velocidade muito rápida não a tempo do resfriamento, isso ocorre por que onde essas águas se localizam há rochas mineralizadas que fazem pressão sobre essas aguas e com isso elas se mantem aquecidas pelo fenômeno denominado de gradiente geotérmico. As águas são realimentadas de forma continua devido a infiltração no solo através das chuvas, rios e lagos.

Silva et al. (2008) relata que a utilização de águas subterrânea nas últimas décadas tornou-se um bem lucrativo, principalmente em relação ao termalismo e o artesianismo, isso porque essas ocorrências se tornam raras ao ponto de vista das possibilidades de ocorrências no Brasil.

[...] Existem no Brasil, assim como em outras partes do mundo, regiões de águas termais, onde o turismo em volta dessa atividade é muitas vezes o responsável pela economia local. O aproveitamento dessas águas através de poços tubulares vem sendo praticado, em muitos casos, sem controle técnico, resultando em processos de super exploração (SILVA et al., 2008).

Devido ao uso dessas águas para o lazer, utilização domestica, industrial, entre outras há uma preocupação com a escassez dessas águas, pois os poços jorram o tempo todo e as piscinas dos Balneários são repostas semanalmente, esse questão é muito importante ser trabalhada pois é dessa água que sobrevivemos e Juscimeira não tem outra fonte que possa fazer o abastecimento e por não haver hidrômetros na cidade o uso é continuo e desenfreado.

Silva et al. (2008) relata que:

[...] Essas atividades poderão ser inviabilizadas, como já acontece em alguns casos, devido à perda ou diminuição do termalismo e/ou artesianismo, principalmente em função do desperdício, onde poços jorram 24 horas por dia, levando o aquífero a sofrer um contínuo rebaixamento potencio métrico.

A Prefeitura Municipal de Juscimeira e o Departamento de Água e esgoto (DAE) preocupados com a possível escassez dessas águas esta realizando o processo de colocação de hidrômetros na cidade pra que os moradores possam economizar água para que não ocorra a falência das águas subterrâneas (Prefeitura de Juscimeira). E para que no futuro não haja a falta de água no mundo é sempre importante sensibilizar os alunos sobre a preservação e o racionamento de água, pois já esta sendo visto a falta de água no Brasil e um caso recente é o de São Paulo, que está sofrendo com essa falta, isso por que não houve um racionamento e nem uma preservação.

\section{Material e Métodos}

Inicialmente foi feito uma breve investigação do conhecimento existente, em seguida foram coletados dados com a pesquisa de campo. Dados que apresentam aspectos importantes sobre a construção de poços artesianos na cidade de JUSCIMEIRA-MT, para que os objetivos sejam alcançados. Neste capítulo foi relatado o local onde se realiza este trabalho, os materiais e a metodologia utilizada. 


\subsection{Descrição da escola}

A Escola Estadual de $1^{\circ}$ Grau Antônio Jose de Lima esta situada na cidade de Juscimeira, Estado de Mato Grosso localizado na área urbana centro da cidade a Rua Emanuel Pinheiro, ${ }^{\circ} 183$ as margens da BR 364.

Fundada em 1978 com a denominação de Escola Estadual de 1ํㅡrau "7 de Setembro", criada pelo Decreto 1.551/78, Diário Oficial 06/10/78. Mais tarde, no ano de 1984, a Escola recebe nova denominação passando a chamar-se Escola Estadual de Grau "Antônio José de Lima, através de Decreto $\mathrm{n}^{\mathrm{o}} 4.643$ de 11/01/84, em homenagem a um dos fundadores da Cidade.

A escola atende aos bairros, centro, alunos da zona rural e assentamentos, alunos na faixa etária de 6 a 14 anos no Ensino Fundamental/Ciclo de Formação Humana e acima de 16 anos na Modalidade EJA, a escola oferece total apoio aos alunos que apresentam dificuldades na aprendizagem atendendo a esses alunos no período oposto com aulas de Apoio Pedagógico. Os métodos avaliativos feito pelo professor continuamente, é através de participação, organização de trabalho, assiduidade, apresentação, leituras, atividades escritas, auto avaliação, trabalhos extraclasse, seminários, pesquisas, disciplina e relatórios bimestrais através das anotações no caderno questões de múltiplas escolhas que leve o aluno a leitura e interpretação.

A escola tem por objetivo posicionar-se de maneira crítica, responsável e construtiva nas diferentes situações, utilizando o diálogo como forma de mediar conflitos e de tomar decisões coletivas. Propiciar ao educando uma educação condizentes com suas expectativas com condições de liberdade de expressão, como princípio norteador do exercício de cidadania.

Manter com toda a Comunidade Escolar, Professores, Servidores, Alunos e Pais de alunos um relacionamento de respeito mútuo, chamando todos para a responsabilidade, do bem estar social, educacional e político da Comunidade Escolar, para que juntos possam desenvolver Projetos de melhoria da Escola, bem como o Ensino Aprendizagem, como suporte básico a realidade escolar.

Somente com a participação de todos é que estará resgatando e construindo o princípio de liberdade, dignidade e cidadania, pois escola apresenta-se como meio norteador e espaço de socialização do saber e de criação dos conhecimentos dos valores éticos e morais.

\subsection{Passos Metodológicos}

Foi realizada a intervenção pedagógica no dia vinte e cinco de março de dois mil e quatorze no período vespertino com os alunos do $6^{\circ}$ ano do ensino fundamental sendo trabalhado o conteúdo de "Aguas termais em Juscimeira" com duração de 4 horas onde foram desenvolvidas aula teórica e aula de campo. Ao perguntarmos sobre águas termais podemos notar que é um tema pouco abordado e desconhecido pelos alunos. Com base nisso estabelecemos os passos metodológicos a serem trabalhados da seguinte maneira:

$1^{\circ}$ Passo: No primeiro momento aplicamos um pré-teste fazendo com que os alunos debatam o tema em grupos a fim de fazer emergir as representações e hipóteses dos mesmos sobre o assunto. Questionário 1

1) O que são águas termais?

2) Como são formadas as águas termais?

Logo após pedir que apresente a classe para termos uma noção do entendimento que os alunos têm sobre o tema proposto, assim apresentamos nossa explicação de como se forma as águas termais na cidade de Juscimeira, e como os cientistas explicam isso darão ênfase de como essa água chega a suas residências.

$2^{\circ}$ Passo: No segundo momento fizemos uma aula de campo no qual observamos um dos locais com poços artesianos que contribuem para o abastecimento da cidade, neste momento os alunos puderam estar obtendo informações de como funciona este abastecimento, a quantidade de água que esses poços jorram por dia, a profundidade e a temperatura dessas aguas. Em seguida fizemos uma visita no SESC Juscimeira, onde observaremos como funciona o fornecimento dessas águas na 
manutenção das piscinas. Neste momento os alunos fizeram entrevista com os funcionários se eles conhecem o porquê de águas termais.

$3^{\circ}$ Passo: Aplicamos um pós-teste para avaliarmos os conhecimentos obtidos pelos alunos, onde pedimos para os alunos que façam um texto do conhecimento obtido.

Questionário 2

1) O que são águas termais?

2) Como são formadas as águas termais?

Por fim esclarecemos dúvidas que tenham ficado em aberto pelos alunos realizando uma revisão de tudo que se foi trabalhado.

\section{Resultados e discussão}

Neste capítulo são apresentados os resultados do planejamento da docência em termos dos passos metodológicos adotados. O PASSO I foi uma aula teórica em sala de aula, o PASSO II foi uma aula de campo com a visita a um dos poços artesianos e ao Serviço Social do Comércio - SESC - Unidade Juscimeira/MT, e por fim como PASSO III foi feita uma avaliação da aprendizagem dos estudantes quanto aos conceitos ensinados.

Este primeiro procedimento foi realizado nas dependências da Escola Antônio Jose de Lima com os alunos do $6^{\circ}$ ano (Figura 1 ).

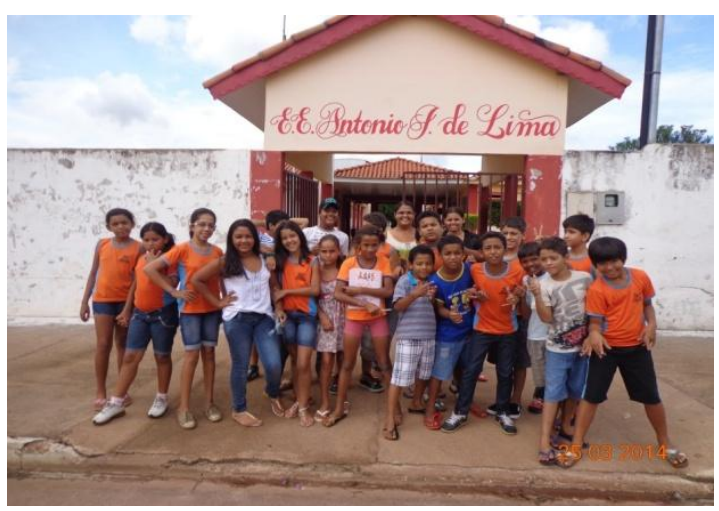

Figura 1 - Estudantes da Escola Estadual Antônio José de Lima (Fonte: Autores).

Ao entrarmos em sala de aula, nos apresentamos formalmente aos alunos e solicitamos que se apresentassem também. Após as apresentações começamos a dialogar com eles sobre a temática adotada para a intervenção, "Águas termais", levando em consideração o fato de Juscimeira/MT possuir ricos mananciais de tais águas, e ainda ressaltando o que vem a ser essas águas termais e como se formam (Figura 2).

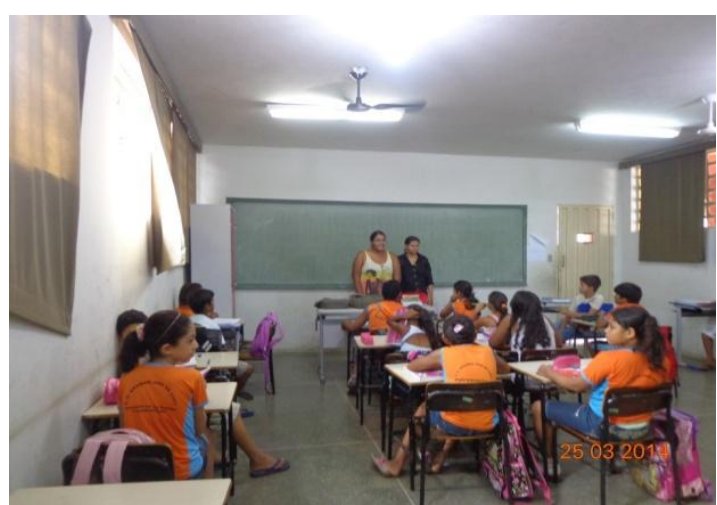

Figura 2- Aula teórica sobre águas termais (Fonte: Autores). 
Por e tratarem de conceitos com pouca discussão e pouco conhecimento buscou-se perceber quais os conhecimentos prévios que estes alunos já haviam adquirido sobre o tema através de um pequeno questionário. Pediu-se aos estudantes para que formassem pequenos grupos de até cinco alunos. Nesses grupos foi possível perceber que a maioria os estudantes não possuíam um conhecimento prévio ou uma noção da formação das águas termais. Desta maneira propomos aos estudantes que respondessem ao questionário e deliberamos no máximo quinze minutos para apresentarem as respostas. Durante a elaboração das respostas os alunos ficaram confusos sobre o que deveriam escrever, pois os mesmo enfatizavam que não haviam estudado sobre o tema, e com isso pedimos a eles que escrevessem sobre o conhecimento que tinham, fossem escolar ou não escolar e que utilizassem sua imaginação para tentar responder as questões. De acordo com Freire (2009) neste momento abrimos um espaço para o conhecimento através do dialogo com prática diferenciada (Figura 3a).

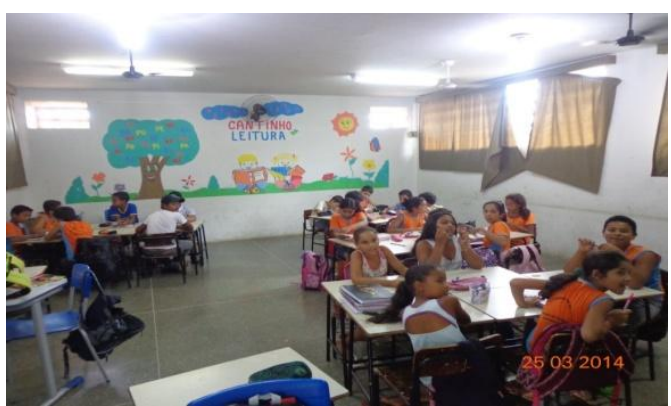

(a)

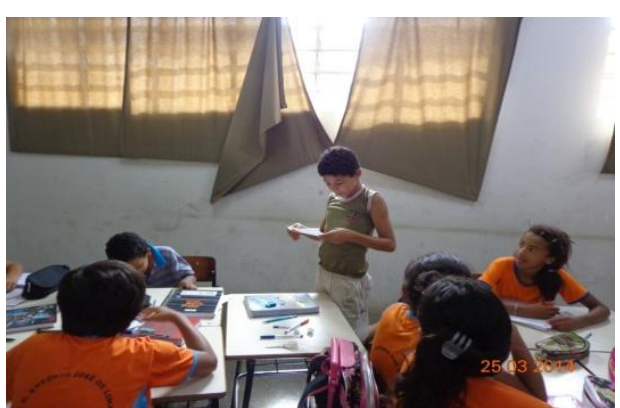

(b)

Figura 3 - (a) Estudantes organizados em grupos para sondagem dos conhecimentos prévios a respeito da temática "águas termais". (b) Discussão do questionário em grupo (Fonte: Autores)

Após o término da escrita das respostas, pedimos para que um estudante de cada grupo lesse as respostas haviam escrito. Nestas leituras pudemos concluir que o tema proposto é pouco conhecido pelos estudantes, e também pouco abordado e/ou ensinado na escola (Figura 3b). Observou-se uma explicação folclórica, proveniente do senso comum, de que as águas eram quentes possivelmente devido a existência de um vulcão, ou ao contato com as rochas quentes da crosta terrestre.

Em seguida iniciamos a nossa explicação esclarecendo a eles o que vem a ser águas termais e como elas são formadas. Durante as explicações sobre as origens das águas termais, e de acordo com Souza \& Orlando (2010), ensinou-se que as águas termais são águas de chuvas que penetram no solo chegando à superfície com temperatura muito elevada com profundidade de cerca de 1500 metros, por conta de fissuras no subsolo; onde se deposita em lençol freático que é comprimido pelo peso das rochas, e devido a isso a água se aquece. Esse fenômeno de aquecimento é denominado de gradiente geotérmico. Essa água do lençol, ao encontrar fissuras na rocha pode subir com rapidez não havendo tempo para o seu resfriamento. As águas são realimentadas de forma continua devido a infiltração no solo através das chuvas, rios e lagos.

Ao finalizar a explanação do conteúdo debatemos com os estudantes sobra duvidas que poderiam aparecido. De acordo com Pillete (2006) para que os alunos pudessem compreender melhor e concretizar o que explicamos foram passados dois vídeos com o uso de projetor multimídia da escola, vídeos esses mostrando visivelmente como ocorre todo o procedimento da formação dessas águas. Durante os vídeos todos os alunos permaneceram atentos, quietos e em seguida foram feitas algumas perguntas direcionadas para verificar o aproveitamento da atividade lúdica. Ao fim da aula em sala, passamos para o próximo passo que foi sair do ambiente escolar e promover uma atividade de campo com a intenção de despertar a curiosidade e a aprendizagem dos alunos (Castro, 2006). Ainda na escola pedimos aos alunos que fizessem perguntas sobre o que haviam aprendido aos funcionários dos locais que iríamos visitar, e se os mesmo conheciam a origem das águas termais.

O Passo II: aula de campo. Inicialmente visitamos o local de um dos poços artesianos que abastecem a cidade. Esses poços que abastecem a distribuição pública de água potável vertem águas quente, e os munícipes recebem água aquecida em suas residências. No poço artesiano visitado, contamos com a ajuda de um funcionário da Prefeitura Municipal de Jucimeira, que se dispôs a 
apresentar as informações técnicas sobre o poço, tais quais, temperatura da água, profundidade do poço, vazão de água e qualidade da água. Os estudantes tiveram a oportunidade de fazer diversas perguntas sobre os poços e foram prontamente respondidas. No entanto, quando os alunos perguntaram ao funcionário se ele sabia o por que dessas águas serem quentes a resposta ficou vaga, e pudemos percebemos que ele não se conhecia a origem dessas águas assim como os estudantes haviam conhecido em sala de aula. Aproveitamos a oportunidade para esclarecer mais uma vez os processos de formação das águas quentes de Jucimeira/MT (Figura 4).

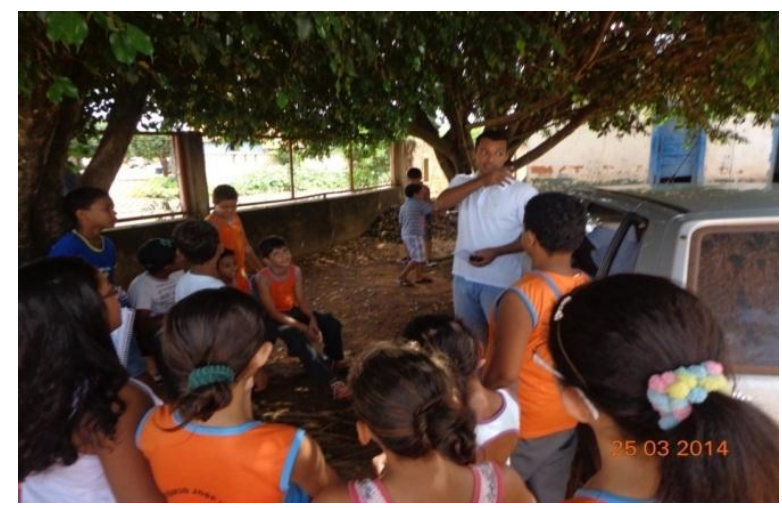

Figura 4 - Conhecendo o departamento de agua de Juscimeira (Fonte: Autores)

Após conhecermos como funciona o abastecimento e distribuição de água da cidade nos dirigimos para o SESC Juscimeira onde foi enfatizada a temperatura da água. Conhecemos também como funciona o abastecimento das piscinas do clube e os processo de manutenção para que as águas das piscinas permaneçam quentes. Os alunos permaneceram muitos curiosos e com muitas perguntas durante a visita ao SESC Jucimeira. Neste local foi feito mais um reforço sobre as águas termais para melhor fixação do assunto (Figura 5).

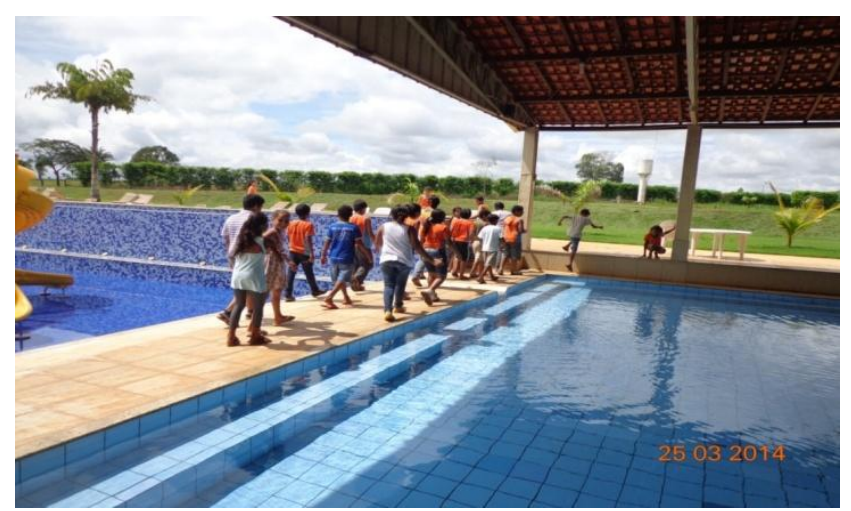

Figura 5 - Visita em um dos Club SESC de Juscimeira (Fonte: Autores)

O Passo III. Ao voltarmos para a sala de aula aplicamos um pós-teste para os estudantes. Pedimos para que fossem formados os mesmos grupos e para avaliar o conhecimento obtido refizemos as mesmas perguntas do inicio da primeira aula. Como desta vez os alunos já haviam estudado sobre o tema esperamos que soubessem responder adequadamente. Os estudantes apresentaram respostas adequadas aos conteúdos ensinados, de maneira que pudemos concluir que todos houve uma 
aprendizagem significativa. Todos os grupos debateram entre si e a escrita foi bem mais desenvolvida do que no primeiro questionário.

Atividades como esta, que utilizam temas geradores e partem do universo vivencial dos estudantes para ensinar ciênicas, além de estimular os estudantes também imprimem satisfação aos professores envolvidos.

\section{Considerações finais}

Neste trabalho foi planejada e executada uma aula com o tema gerador águas quentes. Partindo do senso comum foi ensinado aos estudantes os processos de formação das águas quentes de Jucimeira/MT. As ações foram executadas em três momentos: aula teórica em sala de aula, aula de campo visita orientada à poços artesianos e piscinas de águas quentes, e aula teórica final. A importância de se trabalhar com temáticas do universo vivencial dos alunos faz com que eles se interessam mais pelo o tema abordado, percebemos isso ao se trabalhar água usando uma referência local, e ao leva-los para observar o abastecimento da cidade percebemos que os mesmo se interessaram muito sobre a ocorrência dessas águas, e isso faz com as aulas fiquem mais participativas.

Também percebeu-se importância de trabalhar com algo presente na vida dos alunos faz com que eles se interessam mais pelo o tema abordado, percebemos isso ao se trabalhar água usando uma referência local, e ao leva-los para observar o abastecimento da cidade percebemos que os mesmos se motivassem muito sobre a ocorrência dessas águas, e isso faz com as aulas fiquem mais participativas.

A aula de campo fornece um conhecimento para os alunos que faz com que eles se lembrem do tema, pois você esta vivenciando algo que fica na memória mais do que se estivesse lendo e isso que fornecemos aos alunos, que eles vivenciem essas aulas e aprendam com mais facilidade, percebemos isso na escrita do aluno ao relatar a aula de campo tudo o que foi visto fica muito claro em sua memória.

\section{Agradecimentos}

À Coordenação de Aperfeiçoamento de Pessoal de Nível Superior (CAPES) pelo subsídio através do Programa de Consolidação das Licenciaturas (PRODOCENCIA) Edital 019/2013, processo № 113.657, e do Programa Institucional de Bolsa de Iniciação à Docência (PIBID) Edital № 061/2013, processo № 128.570, IFMT/Campus São Vicente/Sub Projeto Ciências.

\section{Referências}

ALMEIDA, D.; CASARIN, M. A importância de brincar para a construção do conhecimento na Educação Infantil. Revista Educação Especial, v.19, p.45-53, 2002.

BRASIL. Parâmetros Curriculares Nacionais - PCN: Ciências Naturais. Ministério da Educação e do Desporto. Secretaria de Educação Fundamental. Secretaria de Educação Fundamental. Brasília: MEC/SEF, 1997.

CASTRO, E. B. Trilha Interpretativa: Recurso Pedagógico para um Processo de Reflexão-na-ação do Docente de Ciências da Natureza. Cuiabá, 2012. 62p. Dissertação (Mestrado em Ensino de Ciências Naturais) Instituto de Física, Universidade Federal de Mato Grosso.

CUTRIM, A. O.; REBOUÇAS, A. C. Aplicação de sondagem elétrica vertical na estimativa do topo e da espessura de unidade geológicas da Bacia do Paraná na cidade de Rondonópolis-MT. Revista Brasileira de Geofísica (Impresso), v.23, n.1, p.89-98, 2005. 
DELIZOICOV, D.; ANGOTTI, J. A.; PERNAMBUCO, M. M. Ensino de Ciências: fundamentos e métodos. São Paulo: Cortez, 2009.

FAVALLI, L. D.; PESSÔA, K. A.; ANGELO, E. A. Projeto Radix Ciências - Ensino Fundamental II. São Paulo: Scipione, 2009.

FREIRE, P. Pedagogia da autonomia: saberes necessários à prática educativa. São Paulo: Paz e Terra, 2009.

FREIRE, P. Pedagogia do Oprimido. Rio de Janeiro: Paz e Terra, 2005.

MARTINS, I. O papel das representações visuais no ensino-aprendizagem de Ciências. In: ENCONTRO NACIONAL DE PESQUISA EM EDUCAÇÃO EM CIÊNCIAS, 1., 1997, Águas de Lindóia. Anais. Águas de Lindóia: APRAPEC, 1997.

PILLETE, N. Psicologia da Autonomia. São Paulo: Ática, 2006.

SANTOS, B. S (2009). Para uma pedagogia do conflito. In FREITAS, A. L.; MORAES, S. C (Orgs.). Contra o desperdício da experiência. A pedagogia do conflito revisitada. Porto Alegre: Redes Editora Lda., 15-40, 2009.

SILVA, J. J. F.; BELLATO, V.; APOITIA JUNIOR, O. M.; MIGLIORINI, R. B. Estudo hidrogeológico na região de Jaciara, São Pedro da Cipa e Juscimeira, MT. In: XV Congresso Brasileiro de Águas Subterrâneas, São Paulo, 2008.

SOUZA, F. A.; SENRA, R. E. F.; CARBO, L.; MACHADO, N. G.; MELLO, G. J. Estação de tratamento de água e ensino de ciências: uma experiência didática. UNOPAR Científica. Ciências Humanas e Educação, v.15, p.313-319, 2014.

SOUZA, S. P.; ORLANDO, P. H. K. Caldas Novas (GO): Turismo e uso das Águas Termais; XVI Encontro Nacional dos Geógrafos; ENG, 2010. 